\title{
NOTAS SOBRE A EXPERIÊNCIA DE VIDA NUM INTERNATO: ASPECTOS POSITIVOS E NEGATIVOS PARA O DESENVOLVIMENTO DOS INTERNOS
}

\author{
Normanda Araujo de Morais \\ Hilmeri da Silva Leitão" \\ Sílvia Helena Koller" \\ Herculano Ricardo Campos ${ }^{æ}$
}

\begin{abstract}
RESUMO. Este trabalho investiga os aspectos positivos e negativos da experiência de internato para o desenvolvimento de alunos de uma instituição de ensino técnico, a influência da vivência coletiva sobre o desempenho escolar e a concepção sobre um internato ideal. Foram realizadas cinco entrevistas com alunos das três séries do Ensino Médio, com idades entre 15 e 22 anos. Os dados foram analisados a partir da análise de conteúdo. Os aspectos positivos e os negativos da experiência de internato foram apontados a partir da categoria "convivência grupal" (possibilidade de fazer novos amigos $x$ brigas e desentendimentos). As limitações estruturais do internato e a rotina estressante foram as principais implicações percebidas para o desempenho escolar, enquanto o internato ideal foi concebido a partir de mudanças estruturais e da qualidade das relações interpessoais. Os resultados são importantes para a compreensão de contextos educativos desse tipo, os quais são muito pouco referidos na literatura.
\end{abstract}

Palavras-chave: internato, juventude, desenvolvimento.

\section{INVESTIGATING THE EXPERIENCE OF LIVING IN A BOARDING SCHOOL: POSITIVES AND NEGATIVES ASPECTS FOR THE STUDENTS DEVELOPMENT}

\begin{abstract}
This work investigates the positive and negative aspects of the experience of living in a boarding school to the psychological development of students, the influences of the collective experience on the school performance and the conception of an ideal boarding school. Five semi-structured interviews were conducted with 15-22 year-old students. Data was analyzed through content analysis. Both positive and negative aspects of the boarding school experience were pointed out from the group-gathering category (possibility of making new friends versus fights and arguments). The limitations of the boarding school concerning facilities and physical structure, as well as the stressful routine, were the main implications of the collective experience on the school performance. The interns' concept of an ideal boarding school depended on facilities and structure improvements, and on the quality of the relationships. The results are important to educative context comprehension's that received little attention in the literatura.
\end{abstract}

Key words: boarding school; youth; development.

Essa pesquisa foi desenvolvida em uma escola técnica federal localizada no município de Macaíba, RN. A escola apresenta como particularidade um sistema de internato, destinado a estudantes de nível socioeconômico médio e baixo e oriundos de diferentes municípios do Estado, que desejam cursar o Ensino Técnico em Agropecuária e o Ensino Médio.
O objetivo do presente artigo é investigar os aspectos positivos e negativos da experiência de internato para o desenvolvimento de alunos de uma instituição pública federal de ensino técnico, bem como a influência da vivência coletiva sobre o desempenho escolar e a concepção sobre um internato ideal. Busca-se, assim, a partir do levantamento de alguns elementos essenciais relativos à experiência de

* Psicóloga graduada pela UFRN e mestranda em Psicologia do Desenvolvimento pela UFRGS. Apoio CNPq. Integrante do CEPRua (Centro de Estudos Psicológicos sobre meninos e meninas de rua).

\# Psicóloga graduada pela UFRN.

II Docente do Curso de Pós-Graduação em Psicologia do Desenvolvimento - UFRGS, psicóloga, doutora em Educação pela PUCRS. Coordenadora do CEP-Rua (Centro de Estudos Psicológicos sobre meninos e meninas de rua).

x Docente do Curso de Pós-Graduação em Psicologia - UFRN, psicólogo, doutor em Educação pela UFRN. 
vida de "internado", contribuir para a compreensão de contextos educativos desse tipo, os quais são muito pouco referidos na literatura.

\section{SOBRE O "MUNDO DO INTERNATO"}

A compreensão da definição feita por Goffman (1974) sobre o termo "instituição total" é fundamental para o entendimento do sistema de internato. Segundo o autor, trata-se de: "um local de residência e trabalho onde um grande número de indivíduos com situação semelhante, separados da sociedade mais ampla por considerável período de tempo, levam uma vida fechada e formalmente administrada" (p. 11). Esses espaços, dos quais outros exemplos são os hospitais psiquiátricos, as cadeias, as penitenciárias, os quartéis e os conventos, são caracterizados, sobretudo, pelo controle das necessidades humanas, estando os menores segmentos da vida dos internados sujeitos a regulamentos e julgamentos por parte da equipe dirigente.

O controle exercido sobre a vida dos internados pode ser identificado através da seqüência rígida de papéis e horários, proibição de visitas fora de horários previstos e distribuição dos indivíduos nos espaços coletivos. A perda do próprio nome e da aparência usual, através do uso de uniformes, assim como a perda de sentido de segurança pessoal, sugere a violação da reserva de informação quanto ao "eu", ilustrada especialmente pela existência de dormitórios coletivos e banheiros sem porta. Através deste processo, a instituição parece impor ao interno uma disciplina de atividade e uma disciplina de ser que gera mudanças radicais na sua forma de o internado perceber a si e aos outros. Goffman (1974) chama este processo de mortificação do eu, ao passo que Foucault (1975) denomina disciplinarização. Segundo este último autor, nesses locais o controle disciplinar da atividade humana é fator bastante evidente. Dessa forma, a disciplina é imposta com o objetivo de fazer crescer a docilidade e a "utilidade" dos indivíduos, ou seja, a maior obediência destes às regras e normas de funcionamento da instituição. Além disso, segundo Cookson e Persell (2002), o controle das mínimas parcelas da vida do indivíduo tem como objetivo, no quadro de uma escola, transmitir um conteúdo leigo e, ao mesmo tempo, político, para controle e "utilização" dos indivíduos (p. 111).

O internado, por sua vez, desenvolve respostas específicas ao controle exercido sobre ele, seja contribuindo para a estabilidade institucional (nesse caso, ele dá e recebe o que foi sistematicamente planejado), seja escapando daquilo que a organização supõe que ele deve fazer, obter e ser. Nesse último caso, o controle da equipe dirigente feito pelos internados pode se dar através da rejeição da alimentação, da lentidão intencional da produção, da sabotagem de sistemas de luz, água e comunicação, da gozação e desobediência, por exemplo. Nas palavras de Goffman (1974), estes comportamentos assim se expressam:

Onde se espera entusiasmo, haverá apatia; onde se espera afeição, há indiferença; onde se espera freqüência, há faltas; onde se espera robustez, há algum tipo de doença; onde as tarefas devem ser realizadas, há diferentes formas de inatividade. Encontramos inúmeras histórias comuns, cada uma das quais é, ao seu modo, um movimento de liberdade. Sempre que se impõem mundos, se criam submundos (p. 246).

A restrição da liberdade e a limitação do espaço pessoal e da posse de objetos fazem aflorar comportamentos que têm como objetivo confirmar a própria existência do internado. Trata-se, enfim, de modos de comunicação e expressão dos internados, os quais são também formas de auto-afirmação, que refletem a sua busca por uma identidade e servem para devolver a imagem de suas próprias habilidades, capacidade de desafio e do seu próprio poder (Pol, 1996). Nas palavras de Goffman (1974), os comportamentos rechaçados pelas instituições totais são todos expressões de "alguém que tenta separar-se do local em que foi colocado" (p. 248) e de um "santuário pessoal que tenta defender-se" (p. 258).

Outra perspectiva válida de análise sobre o internato é dada pela Psicologia Ambiental, que tem desenvolvido várias pesquisas em ambientes desse tipo. Em linhas gerais, a Psicologia Ambiental dedicase ao estudo da inter-relação pessoa-ambiente e compreende as relações humanas como sendo afetadas pelo espaço físico onde se desenvolvem (Torvisco, 1998).

A fim de entender como essas interações ocorrem é necessário estar atento ao tamanho das habitações, à forma como ela está organizada (com grandes ou pequenos quartos, banheiros coletivos ou de uso individual) e, principalmente, à densidade de ocupação (número de pessoas/espaço disponível). A alta densidade constitui a principal característica dos internatos. Esse tipo de ambiente é freqüentemente associado com encontros não desejados e não previstos, ou seja, com a perda do sentimento de privacidade, que diz respeito à capacidade do indivíduo de controlar o seu contato social com o 
grupo e outros residentes (Holahan \& Wandersman, 1987; Valera \& Vidal, 1998).

A dificuldade em regular a natureza e a freqüência das interações sociais, ou seja, em "regular quando, onde e com quem eles poderiam interagir" (Hombrados, 1998, p. 549) levaria ao que esse autor chama hacinamiento e ao que Baum e Paulos (1987) denominam crownding. Em português, estes termos equivalem a "aglomeração". Em resumo, o hacinamiento ou crownding refere-se a um estado subjetivo, a uma experiência psicológica originada da demanda de espaço por parte do indivíduo que excede o disponível e gera, como já relatado, a perda de privacidade e de espaço pessoal.

Conforme afirmam Hombrados (1998) e Baum e Paulos (1987), os efeitos sociais e psicológicos do hacinamiento sobre os residentes são comprovadamente negativos. Tais efeitos são expressos pelo prejuízo na produção de tarefas e no rendimento, pelo aumento de reações de agressividade, hostilidade e mal-estar e pela diminuição nas condutas de afeto entre os sujeitos. Outras possíveis consequiências são o incremento da possibilidade de transmissão de enfermidades (sobretudo as produzidas por contágio) e da vulnerabilidade ao estresse. Além disso, Hombrados (1998) afirma que os indivíduos que tendem a vivenciar esses sentimentos e o estresse decorrente deles nas residências estudantis "rendem menos e cometem mais falhas na solução de problemas no contexto da aula, manifestam mais problemas de saúde e desenvolvem condutas de isolamento." (p.169)

A experiência de hacinamiento ou crownding pelo indivíduo deve ser avaliada pela análise do contexto - nível de densidade, ruído e organização social -e também pelo estudo das suas características pessoais e culturais - estratégias de enfrentamento de uma situação, necessidade de privacidade, qualidade da interação, posição do indivíduo no grupo e o grau de adaptabilidade ao mesmo.

A fim de prevenir a aparição do hacinamiento em internados, Holahan e Wandersman (1987) sugerem que o ambiente seja organizado de forma a fornecer espaços de maior privacidade, que seja facilitada a formação de pequenos grupos e incentivada a habilidade dos indivíduos em controlar as interações sociais não desejadas. $\mathrm{O}$ menor tamanho do grupo permite o melhor desenvolvimento de mecanismos para regular as interações sociais, como a formação de normas, por exemplo, e a familiarização com outros membros do grupo (Baum \& Paulos, 1987).

A literatura acima destacada tende, destarte, a fazer uma caracterização do regime de internato a partir das limitações pessoais colocadas aos internos (controle das mínimas parcelas de vida, diminuição da privacidade, etc.). Ao mesmo tempo, também não se encontram na literatura referências a esse espaço como um "contexto educativo" e à sua influência sobre o desenvolvimento (cognitivo, social e emocional) dos internados.

É visando, assim, a preencher essa lacuna que o presente artigo busca caracterizar e destacar algumas implicações desenvolvimentais da experiência de vida num internato para alunos do ensino médio de uma instituição pública federal de ensino técnico. Para isso, investigará quais os aspectos positivos e negativos destacados pelos internos sobre a experiência de internato, qual a influência desta sobre o desempenho escolar e qual a concepção sobre um internato ideal.

\section{CARACTERIZAÇÃO DO INTERNATO}

O internato é oferecido a dois tipos de clientela: 1) alunos que conciliam o curso de agropecuária e o Ensino Médio (em dois turnos), advindos de diferentes municípios do interior do Estado; e, 2) alunos membros da Federação dos Trabalhadores da Agricultura do Rio Grande do Norte (FETARN), que cursam (nos dois turnos) somente o técnico em agropecuária. Destaca-se entre esses dois grupos uma diferença significativa de faixa etária quando do seu ingresso na escola e no internato, sendo os alunos do primeiro grupo concluintes do Ensino Fundamental (14-15 anos) e os do segundo grupo, trabalhadores rurais, com Ensino Médio já concluído (20 anos ou acima), que voltaram para a sala de aula em busca de qualificação profissional.

No total, são dois alojamentos masculinos e um feminino. O alojamento I masculino conta com seis quartos, sendo quatro deles com doze pessoas e dois menores com seis; o alojamento II conta com cinco quartos, sendo um deles com quatro pessoas e os demais com doze. Somente o alojamento I conta com uma sala de estudo. Entre os dois blocos existe uma sala de televisão de uso comum e, em ambos, os banheiros são coletivos. Já no alojamento feminino são quatro quartos, cada um com nove meninas. $\mathrm{O}$ banheiro também é coletivo, não existe sala de estudo, somente uma pequena sala de estar, além de uma cozinha e um quintal.

O alojamento feminino mostra-se mais limpo e acolhedor, sendo a organização do seu espaço semelhante à de uma casa. Ao contrário, os alojamentos masculinos lembram mais a estrutura de um presídio, dada a altura do prédio, a largura das portas e a escuridão. 
Os alunos internos têm horários rígidos para levantar pela manhã, recolher-se à noite e fazer as refeições. Além de freqüentar as aulas nos dois turnos e os estágios no campo, eles também são os principais responsáveis pela limpeza dos alojamentos. As questões disciplinares e do dia-a-dia do internato (distribuição do material de limpeza, resolução de conflitos, etc.), estão sob a responsabilidade dos inspetores e de um coordenador geral. Os inspetores são funcionários da escola e possuem o Ensino Médio. Já o coordenador geral tem o nível superior e faz parte do corpo de professores da escola. O internato é mantido pelos recursos federais destinados à instituição, não sendo, por isso, cobrada nenhuma taxa aos alunos.

\section{MÉTODO}

\section{Participantes}

Dos cinco residentes entrevistados, três eram adolescentes do sexo masculino e dois do sexo feminino; tinham entre 15-22 anos $(\mathrm{m}=17,4$ anos; DP $=2,7)$ e eram todos provenientes do interior do Estado. O objetivo era entrevistar dois alunos (um de cada sexo) de cada série do Ensino Médio (E.M), porém, em virtude da falta de disponibilidade da aluna do segundo ano, sua entrevista não pôde ser concluída.

\section{Instrumentos e procedimentos}

A fim de aproximar-se da realidade do internato e alcançar os objetivos propostos foram realizadas cinco entrevistas semi-estruturadas. Os entrevistados foram escolhidos por conveniência e a partir da sua disponibilidade inicial. Informações complementares referentes às temáticas da pesquisa foram conseguidas através de atividades em momentos diferentes, ao longo de um ano de inserção das pesquisadoras no ambiente de pesquisa (observações, oficinas com os internos, dinâmicas de grupo em sala de aula, conversas informais, participação nas reuniões de professores, etc.). A esse processo de estudo do desenvolvimento-no-contexto, desenvolvido por Cecconello e Koller (2003), dá-se o nome de inserção ecológica. Este método, baseado na Abordagem Ecológica do Desenvolvimento Humano de Urie Bronfenbrenner (1979/1996), privilegia a inserção do pesquisador no ambiente de pesquisa com o objetivo de estabelecer proximidade com o seu objeto de estudo e, assim, responder às questões de pesquisa. Dessa forma, o conteúdo das entrevistas pode ser compreendido à luz da devida contextualização que a presença e a participação das pesquisadoras no ambiente de pesquisa possibilitam.

$\mathrm{O}$ roteiro de entrevista semi-estruturada contava com questões sobre a caracterização sociodemográfica dos participantes, a sua avaliação de "como é viver no internato", "quais os aspectos que mais gostam e os que menos gostam dessa experiência", assim como qual a sua "percepção sobre a influência da vivência coletiva sobre o seu desempenho escolar" e a "concepção sobre um internato ideal".

Antes da realização das entrevistas, os participantes receberam as explicações sobre o propósito da pesquisa e a garantia acerca do sigilo de sua identidade. Somente após mostrarem-se de acordo e terem suas dúvidas esclarecidas é que foram entrevistados.

\section{RESULTADOS E DISCUSSÃO}

Os resultados serão apresentados e discutidos a partir de três unidades temáticas principais que emergiram da análise de conteúdo (Bardin 1977/1979): avaliação sobre como é viver no internato (aspectos positivos e negativos da experiência), percepção da vivência em ambiente coletivo sobre o desempenho escolar e concepção sobre um internato ideal.

\section{Avaliação sobre como é viver no internato}

Todos os alunos entrevistados destacaram o valor positivo dessa experiência, em virtude, sobretudo, da possibilidade de conviver com pessoas diferentes. Informaram, ainda, o seu desejo de ingressar na escola e que o internato foi um elemento motivador para isto. Tal motivação baseou-se em questões práticas, ou seja, ter onde morar e poder conciliar dois cursos. A possibilidade vislumbrada de relativa independência familiar e amadurecimento pessoal também foi destacada como justificativa para a avaliação final positiva feita pelos internos sobre "como é viver no internato."

Bem, pra mim é uma experiência e tanto. Se todos os jovens tivessem uma experiência como essa que a gente tem aqui no internato, seria bom demais (...) quando você chega aqui no internato, você vai viver num mundo diferente, mil e uma cabeças diferentes, costumes diferentes, palavras diferentes que você nunca tinha ouvido falar (...) (Carlos, 17 anos, $1^{\circ}$ E.M)

É a questão de ter gente de todos os gênios (...) Quando você ta (...) você mora em casa, 
você acha que a única pessoa que existe é você (...) que só existe pessoas de seu tipo. Mas quando você sai de...perde a mordomia, aí você vê que tem pessoas, gente diferente (...) (João, 16 anos, $2^{\circ}$ E.M)

De forma geral, todos os entrevistados avaliaram a experiência de viver no internato como um importante momento de suas vidas, que lhes ficará marcado na memória. Para isso, destacaram o amadurecimento pessoal alcançado em virtude das amizades conquistadas e das dificuldades enfrentadas, assim como pelas possibilidades de reflexão e mudança em suas ações. Esses ganhos contribuíram, inclusive, para a ressignificação de si mesmos e da experiência de internato e para tornar secundárias as dificuldades enfrentadas e experiências negativas.

É bom estar aqui. Minha vida mudou muito (André, 22 anos, $3^{\circ}$ E.M).

(...) Nenhum canto eu acho que você vai encontrar esse local aqui, uma família... Somos todos quase que nem irmãos, uma casa que você chega que tem irmãos diferentes, a casa de amigos que vou guardar pra sempre junto da gente, nunca vou me esquecer, o melhor momento da nossa vida é aqui (Carlos, 17 anos, $1^{\circ}$ E.M).

É uma experiência muito boa, como é que eu posso dizer, é um pequeno mundo num grande mundo. (...) Em nenhum momento eu me arrependo de ter vindo pra cá. (...) São coisas que a gente tem que viver, né? (Bruna, 17 anos, $3^{\circ}$ E.M).

\section{Aspectos positivos da experiência de internato}

Quando perguntados sobre o que "mais gostam" da experiência de internato, os participantes destacaram a possibilidade de fazer novos amigos e a oportunidade de conviver diariamente com eles.

O que eu mais gosto (...) você pode tá $24 \mathrm{~h}$ com amigos(...) (João, 16 anos, $2^{\circ}$ E.M).

$\mathrm{O}$ que eu mais gosto no internato são as pessoas sinceras. São as pessoas que dizem ser realmente seus amigos, seus companheiros do dia-a-dia, seus colegas de classe, são as pessoas pra conversar, são as pessoas pra dividir os problemas e achar as soluções (...) Eu tenho grandes amigos lá dentro, grandes irmãos, grandes irmãos meus(...) (André, 22 anos, $3^{\circ}$ E.M).

Realmente, eu gosto muito assim de conversar, sabe, de estar entre amigos, conversando, debatendo(...) (Bruna, 17 anos, $3^{\circ}$ E.M).

A existência de vínculos afetivos significativos entre os alunos, sejam eles das relações estabelecidas de amizade ou de namoro, são importantes tanto pelo seu papel socializador e de formação de identidade como também por permitirem que os adolescentes partilhem o conhecimento, já que eles podem constantemente estudar juntos. A importância dada à existência desses vínculos corrobora a noção de que, na adolescência, os relacionamentos com outros indivíduos e com grupos diversos, diferentes da família, são enfatizados (Newcombe, 1996/1999). A escola, em especial, o internato, é um espaço profícuo e fundamental ao estabelecimento dessas relações, que podem marcar de forma decisiva a vida desses adolescentes.

Steinberg (1985/1996) afirma que a valorização das amizades e do relacionamento com pares na adolescência está relacionada ao desenvolvimento da intimidade. Esta consiste no estabelecimento de relacionamentos mais próximos, pessoais, de maior envolvimento emocional e auto-revelação. Apesar de as relações próximas serem extremamente importantes para pessoas de todas as idades, é na adolescência que emergem as primeiras relações verdadeiramente íntimas. Dessa forma, se as relações de amizade até então costumavam ser orientadas pelas atividades (brincar, estudar, etc.), na adolescência tornam-se mais autoconscientes e mais analíticas, sendo construídas a partir do estabelecimento de vínculos afetivos.

Outra importante característica psicossocial da adolescência destacada por Steinberg (1985/1996) é a da autonomia. Assim como a intimidade, a autonomia também é especialmente saliente durante a adolescência, devido às mudanças físicas, cognitivas e sociais do período. Em linhas gerais, a autonomia diz respeito à capacidade da pessoa de autogovernar-se, o que envolve tanto o componente comportamental quanto o emocional e o cognitivo. Dessa forma, são destacados três tipos de autonomia: 1) autonomia emocional, referente à independência emocional, sobretudo com relação aos pais; 2) autonomia comportamental, relacionada à capacidade de tomar decisões independentes e orientar o seu comportamento por elas; e, 3) autonomia de valor, que diz respeito ao desenvolvimento independente de crenças e valores sobre o que é certo e errado, importante ou não.

Por fim, vale destacar a ressalva de que o desenvolvimento da autonomia (individuação) não necessariamente envolve conflito, ruptura e rebelião contra as pessoas (pais e educadores, por exemplo) e 
valores vigentes. Trata-se, muito mais, de um processo que tende a ser mais pacífico e menos tumultuado quanto maior for o grau de proximidade das pessoas em relação (pais e filhos, adolescentes e educadores, por exemplo). Dessa forma, práticas educacionais "autorizadas", as quais são caracterizadas pela amizade, justiça e firmeza, tendem a encorajar independência, responsabilidade e auto-estima das pessoas envolvidas. Essa visão rompe, portanto, com a noção de que a adolescência seria a priori uma fase de "tempestade e tormenta". Ao fazer isso, destaca a influência sobre o desenvolvimento humano dos vários tipos de contexto e da qualidade das interações estabelecidas entre as pessoas nele presentes. Daí afirmar-se que o desenvolvimento psicológico positivo refere-se à capacidade do adolescente de funcionar tanto independentemente quanto interdependentemente, através do estabelecimento de relações satisfatórias e saudáveis com outros.

\section{Aspectos negativos da experiência de internato}

Ao mesmo tempo que a possibilidade de conviver com amigos o maior período de tempo possível é visto pelos participantes como um aspecto positivo, verifica-se que os aspectos negativos apontados por eles também estão estreitamente relacionados com as particularidades da convivência em grupo. Dessa forma, brigas, desentendimentos, rivalidades, intrigas, jogos de interesse e incompreensão foram identificados como os aspectos negativos, bastante presentes em seu cotidiano, os quais eles gostariam que não existissem. Outros aspectos destacados como negativos, em menor freqüência, foram: a deficiência na higienização, sobretudo no alojamento masculino, as instalações precárias dos alojamentos, a má qualidade da alimentação e a falta de um acompanhamento mais próximo junto aos alunos por parte da equipe responsável pelo internato. Os trechos abaixo ilustram os aspectos vistos como negativos.

(...) É triste dizer, mas tem uma falsidade muito grande e um jogo de interesse, né? Você percebe assim que, às vezes, as pessoas são seus amigos porque querem alguma coisa de você, tá entendendo? (Bruna, 17 anos, $3^{\circ}$ E.M).

Tem umas que bagunçam, outras que são mais organizadas, outras que (...) tem muito desentendimento com outras (Alice, 15 anos, $1^{\circ}$ E.M).

A origem dos conflitos geralmente está relacionada com o choque de interesses entre os internos, o que pode ser exemplificado da seguinte forma:
Muitas vezes você tá no quarto, quer estudar, tá com som ligado, os outros zuando, aí num liga (...) Aí muitas vezes você tá com uma dúvida, discutindo com outro colega, aí o outro que tá atrás de dormir diz: 'Não, não sei o quê (...) Você fez isso pra provocar'. Aí, aquele atrito! (Carlos, 17 anos, $1^{\circ}$ E.M)

(...) É som ligado a toda hora do dia, as meninas falam muito alto, sabe? No banheiro (...) é uma falta de respeito, porque as meninas iam tomar banho, ficavam gritando mesmo, assim, absurdos (...) gritos mesmo! Ficavam 20 minutos no banheiro, sabendo que tinha pessoas fora, sabe, pra tomar banho (...) (Bruna, 17 anos, $3^{\circ}$ E.M).

A dificuldade de relacionamento interpessoal apontada pelos alunos não é contraditória com a importância atribuída por eles ao estabelecimento das amizades, uma vez que esses conflitos são também constitutivos das interações sociais, fazendo parte do cotidiano. A origem dos conflitos estava relacionada, principalmente, à quebra de regras estabelecidas (som com volume muito alto, gritos, luz acesa fora de hora, não-obediência à escala de limpeza) e às limitações estruturais do internato (número elevado de alojados por quarto, banheiros coletivos e falta de ambiente adequado para o estudo).

\section{Influência do ambiente coletivo sobre o desempenho escolar}

A principal relação identificada pelos alunos entre esses dois aspectos diz respeito à inexistência de um ambiente adequado para o estudo. Os internos destacaram que a bagunça e o barulho tornam o ambiente do alojamento impróprio para o estudo, exigindo deles a busca por novos espaços mais tranquiilos ou mesmo de outras estratégias, como acordar mais cedo para estudar.

Aqui embaixo as salas estavam fechadas. A biblioteca que deveria ter um silencinho maior sabe, também não consegui estudar lá. Aí eu, 'Onde é que eu vou estudar?'. No meu quarto eu também não tava conseguindo estudar. Então, o que é que eu faço? Aí eu desci, consegui uma sala aqui e fiquei estudando com os meninos (Bruna, 17 anos, $3^{\circ}$ E.M)

$\mathrm{O}$ único ambiente que tem no alojamento feminino pra estudar é a sala, porque no quarto tem gente que quer dormir e a luz não pode ficar acesa. Aí elas começam a fazer zuada, começam a bagunçar, aí não tem como a gente estudar. (...) Às vezes eu 
acordo cedinho pra estudar quando não dá tempo de estudar à noite (Alice, 15 anos, $1^{\circ}$ E.M).

(...) A gente tem que sair, a gente...lá do conforto dos nossos beliches, do nosso colchão, para uma cadeira dura, uma calçada dura dessa daí para estudar, porque já que dentro do internato tem aquele clima e, muitas vezes, há confusão lá, você já sai com a cabeça estourando de dor de cabeça lá das confusões (Carlos, 17 anos, $1^{\circ}$ E.M).

Viver em um local onde "você não está dividindo trabalho e estudo. Você só tem compromisso com o estudo." foi um aspecto ressaltado como importante principalmente por André (22 anos). No entanto, todos os outros participantes destacaram a complexidade dessa questão, afirmando que o fato de morar e estudar no mesmo local não é, por si só, garantia de sucesso. Outra dificuldade, além da falta de ambiente propício ao estudo, já referida acima, parece ser administrar o tempo, não só entre as diversas atividades curriculares, mas com outras, como: conversar com amigos, namorar, participar do teatro e do grêmio. Essa dificuldade é percebida principalmente no discurso de João. Os demais parecem conciliar melhor.

(...) Se eu fosse externo eu não teria tanto tempo de estudar é (...) e quando chegasse em casa já ia tá tarde e já ia tá cansado. Mas tem aquela outra (...) a contradição aqui no aloja (...) aqui no (...) no internato, porque você pode ter um tempo a mais, mas só que você não consegue, porque sempre aparece um, um, um colega oferecendo coisa pra você fazer. (...) Em um ambiente coletivo você não consegue estudar como você estudaria em casa, na sua (...) na sua casa, no seu lugar reservado. Porque aqui no colégio (...) aqui num tem um, um local específico, restrito para, pra estudo. (...) porque no alojamento tem uma sala de estudo, mas a sala de estudo dentro do alojamento acho que não combina porque é (...) fica no corredor e qualquer barulho incomoda lá na sala de estudo. (...) Se eu tivesse em casa, eu tenho certeza que eu saberia mais é (...) dividir meu tempo. E (...) até o ano passado eu tava tentando controlar, mas eu não sei porque motivo (...é (...) esse ano é (...) Eu acho um pouco difícil, assim, tentar controlar o tempo, porque tudo pra você é novidade quando você sai de casa. (João, 16 anos, $2^{\circ}$ E.M)

Um outro aspecto ressaltado em todos os depoimentos se referiu à existência de uma rotina diária bastante estressante, dadas as atividades que têm que cumprir em horários bem determinados (aulas nos dois turnos, estágios, refeições). Diante dessa exigência, os entrevistados falaram da necessidade de serem bastante sistemáticos, organizando bem os seus horários.

Aqui é assim (...) você tem que saber separar, dizer 'tal hora vou estudar, tal hora vou fazer isso, tal hora vou fazer aquilo, vou dormir pra acordar tal hora', tudo programado aqui. É igual a um robô, aqui você tem que tá programado (Carlos, 17 anos, $1^{\circ}$ E.M).

A rotina estressante a qual os alunos estão submetidos é, muitas vezes, fonte de angústia para eles. Uma vez que têm que conciliar dois cursos e estágios, o tempo que lhes resta é somente a noite. A quantidade de trabalhos e provas é grande, não há nenhuma articulação entre os dois cursos (Técnico em Agropecuária e Ensino Médio) e eles ainda têm que dar conta de outras atividades, como a limpeza dos quartos. Essa angústia e dificuldade dos alunos em conciliar as diversas atividades é verificada, principalmente, quando querem dispor de tempo para conversar com amigos, namorar, participar do teatro, do grêmio e do grupo de orientação profissional.

\section{Concepção sobre um internato ideal}

Para os alunos entrevistados, um internato ideal deveria possuir principalmente, assim como destacado por Holahan e Wandersman (1987) e Baum e Paulus (1987), um menor número de alojados por quarto e um melhor relacionamento entre os internos, que deveriam respeitar-se mutuamente e ser solidários uns com os outros. Outras sugestões foram feitas, como: a existência de banheiros integrados ao quarto (e não coletivos), melhor limpeza dos quartos e banheiros, seguimento das regras e organização do internato por casa e não por bloco. Até mesmo um sistema de filmagem nos quartos, a fim de identificar os verdadeiros "culpados" ou "inocentes" no cumprimento das regras foi sugerido. Não por acaso, pois entre os alunos é identificado um certo temor da possibilidade de perda do internato, caso alguma das suas normas sejam quebradas. Nas palavras de um dos entrevistados:

Você tem que se agüentar para não quebrar as regras aqui, se brigar, perde o internato. (...) $\mathrm{O}$ maior medo aqui é perder o internato. Tudo você vai fazer, se você fizer isso você perde o internato, o cara já desiste (Carlos, 17 anos, $1^{\circ}$ E.M). 


\section{CONSIDERAÇÕES FINAIS}

Dar "voz" aos alunos internos foi um processo de fundamental importância para a compreensão de como a sua subjetividade e o seu desenvolvimento estão se configurando a partir da experiência de vida nesse contexto particular e da sua interação com os outros indivíduos. Conforme afirma Chaves (2002), é nessas interações que cada indivíduo constrói suas formas particulares de pensar, sentir e agir, usando para isso tanto de significados culturais compartilhados pelo grupo como da atribuição de um sentido pessoal, que age ressignificando o primeiro.

Destarte, ao escutar cada adolescente - seja através das entrevistas seja pelas observações e trabalhos em grupo - , foi possível ter acesso a aspectos comuns e particulares de suas experiências. Estes aspectos, por sua vez, não só confirmaram a forma como o internato vem sendo descrito na literatura, mas também serviram para despertar a atenção para os aspectos positivos da experiência de internato, pouco destacados pela literatura pesquisada.

Enquanto uma "instituição total", o internato caracteriza-se por dois aspectos principais, que se encontram diretamente relacionados. $\mathrm{O}$ primeiro deles diz respeito ao controle exercido sobre a vida dos internos, e pode ser identificado pela sequiência rígida de horários a ser cumprida, pelos papéis a serem desempenhados e pela existência de um regimento que tem como objetivo punir os comportamentos não desejados. Já o segundo, refere-se à maneira peculiar como o espaço do internato está organizado. Esta forma de organização é estabelecida de modo a reforçar o controle e influenciar a relação dos internos consigo e com os demais. Nesse sentido, o elevado número de indivíduos por quarto, a existência de banheiros coletivos e a falta de ambientes adequados à realização de algumas tarefas, como estudar, por exemplo, tendem a gerar a perda do sentimento de privacidade, que diz respeito à capacidade do interno de regular as suas interações sociais (onde, quando e com quem relacionar-se). Esse sentimento, por sua vez, contribui para o surgimento de comportamentos (conflitos interpessoais, vandalismo, falta de higiene, atraso para as aulas) bastante presentes no cotidiano desses adolescentes. Esses comportamentos foram apontados como queixa tanto pelos adolescentes quanto pelos monitores responsáveis pelo internato e pelos professores da escola, nos diversos momentos informais de conversa entre estes e as pesquisadoras.

Algumas medidas poderiam contribuir para a minimização das dificuldades identificadas pelos internos: 1) a existência de um acompanhamento sistemático e mais próximo por parte da equipe de inspetores e coordenadores; 2) a melhoria na infraestrutura do internato (menor número de alojados por quarto, existência de banheiros integrados ao quarto e de local adequado ao estudo, melhor limpeza dos alojamentos, etc.); e, 3) a realização de um trabalho de grupo que possibilitasse a reflexão permanente dos internos acerca de aspectos como comunicação, liderança, conflitos, cooperação, os quais fazem parte da vida em ambiente coletivo.

Sobre o acompanhamento mais sistemático por parte da equipe, duas ressalvas são feitas: a primeira é a de que os próprios internos sentem falta da presença de um "mediador", não só nas ocasiões de conflito, mas também em outras situações nas quais eles precisam recorrer a alguém de referência. A segunda trata da necessidade de que essa pessoa de referência não seja alguém distante e autoritário, mas alguém que eles respeitem e que exerça a autoridade necessária. De acordo com Bronfenbrenner (1979/1996), entre educadores (inspetores e coordenadores) e internos deveriam ser estabelecidas relações de reciprocidade, marcadas por uma mutualidade de sentimentos positivos e pela alteração gradual no equilíbrio de poder. Este equilíbrio ocorre no momento em que o poder se altera em favor da pessoa em desenvolvimento, ou seja, deixa de centralizar-se unicamente nas mãos dos inspetores e coordenadores, permitindo ao adolescente pensar e agir modificando as diferentes situações por ele vividas. Bronfenbrenner (1979/1996) acrescenta que essa representa uma situação ideal para a aprendizagem e desenvolvimento do adolescente.

No que se refere às dificuldades identificadas pelos internos para administrar o seu tempo e cumprir a elevada carga de atividades escolares, destacam-se duas alternativas de solucioná-las ou amenizá-las. Trata-se, assim, da necessidade de se repensarem os currículos de cada curso (E.M e Técnico em Agropecuária), proporcionando uma maior integração dos seus conteúdos, bem como da criação de um espaço de discussão conjunta entre equipe dirigente e alunos acerca da rotina da escola.

As considerações acerca das dificuldades identificadas pelos internos, assim como de possibilidades concretas de resolução das mesmas, apontam para uma importante perspectiva de análise dos comportamentos dos internos. Estes, longe de serem vistos como um problema individual, passam a ser entendidos como respostas a uma forma de organização peculiar do regime de internato, o qual se estrutura impondo ao internado um rígido controle e uma disciplina de ser que tolhem as mínimas 
expressões de sua singularidade. Segundo Cookson e Persell (2002), ao agir assim, a escola cumpre com a sua função de reprodutora da sociedade e de reforçadora do status quo, já que treina e socializa os jovens no mundo material e simbólico da geração de seus pais.

Apesar de os fatores citados serem relevantes à compreensão da dinâmica do internato, é importante ressaltar que eles refletem apenas um lado da vida nesse espaço, já que tratam somente dos aspectos negativos. Assim, uma análise mais próxima e coerente da realidade exige a consideração de uma outra dimensão, que diz respeito ao que de positivo há na experiência de viver em contextos educativos como esse. Conforme visto, os vínculos afetivos e o amadurecimento pessoal alcançados foram aspectos bastante destacados pelos entrevistados. Conseqüentemente, é possível salientar a importância desse espaço, no qual o convívio com pessoas diferentes e com situações que exigem a resolução de problemas (administração de horários, tarefas, conflitos interpessoais, a separação da família) pode levar ao desenvolvimento dos sentimentos de cooperação, solidariedade e identidade grupal, além da intimidade e da autonomia em administrar a própria vida.

Ressalta-se, assim, a necessidade de uma análise que considere o internato na sua complexidade. Esse fato implica o conhecimento global da instituição na qual o internato está inserido e é somente mais uma parte, assim como do próprio ambiente do internato e das relações estabelecidas entre os indivíduos nesse espaço.

\section{REFERÊNCIAS}

Baum, A. \& Paulos, P. (1987). Crownding. Em D. Stokols \& I. Altman (Org.), Handbook of environmental psychology (pp. 548726). New York: Wiley Interscience.

Bardin, L. (1979). Análise de conteúdo (L. A. Reto \& A. Pinheiro, Trad.). São Paulo: Edições 70/Livraria Martins Fontes. ( Trabalho original publicado em 1977)

Bronfenbrenner, U. (1996). A ecologia do desenvolvimento humano: Experimentos naturais e planejados. Porto Alegre: Artes Medicas. (Trabalho original publicado em 1979)
Cecconello, A. M. \& Koller, S. H. (2003). Inserção ecológica na comunidade: Uma proposta metodológica para o estudo de famílias em situação de risco. Psicologia Reflexão e Crítica,16(3), 515-524.

Chaves, A. M. (2002). A vida e o viver em um internato: o ponto de vista de um grupo de meninos residentes. Em E. R. Lordelo; A. M. A. Carvalho \& S. H. Koller (Orgs.), Infância brasileira e contextos de desenvolvimento (pp. 45-75). São Paulo/Salvador: Casa do Psicólogo/EDUFBA.

Cookson, P. W. \& Persell, C. H. (2002). Internatos americanos e ingleses: um estudo comparativo sobre a reprodução das elites (A. M. F. Almeida, Trad.). Em A. M. F. Almeida \& M. A. Nogueira (Orgs.), A escolarização das elites (pp. 103-119). Petrópolis: Vozes.

Foucault, M. (1975). Vigiar e punir: história da violência nas prisões. Petrópolis: Vozes.

Goffman, E. (1974). Manicômios, prisões e conventos. São Paulo: Perspectiva.

Holahan, C. J. \& Wandersman, A. (1987). The community psychology perspective in environmental psychology, Em D. Stokols \& I. Altman (Org.), Handbook of environmental psychology (pp. 835-837). New York: Wiley Interscience.

Hombrados, M. I. (1998). Hacinamiento. Em J. I. Aragonès \& M. Américo (Orgs.), Psicologia ambiental (pp. 149-171). Madrid: Pirámide.

Newcombe, N. (1999). Desenvolvimento infantil: abordagem de Mussen $\left(8^{\circ}\right.$ ed.). Porto Alegre: Artes Médicas. (Trabalho original publicado em 1996)

Steinberg, L. (1996). Adolescence. New York: McGraw-Hill. (Trabalho original publicado em 1985)

Pol, E. (1996). La apropiación del espacio. Em L. Íñiguez \& E. Pol (Orgs.), Cognición, representación y apropriación del espácio (Colección Monografies Psico-Socio-Ambientals, Vol. 9, pp. 4562). Barcelona: Publications de la Unmiversitat de Barcelona.

Torvisco, J. M. (1998). Espacio personal y ecologia del pequeño grupo. Em J. I. Aragonès \& M. Américo (Orgs.), Psicologia ambiental (pp. 548-726). Madrid: Pirámide.

Valera, S \& Vidal, T. (1998). Privacidad y territorialidad. Em J. I. Aragonès \& M. Américo (Orgs.), Psicologia ambiental (pp. 123147). Madrid: Pirámide. 